AperTO - Archivio Istituzionale Open Access dell'Università di Torino

Rapid Identification of Microorganisms from Positive Blood Culture by MALDI-TOF MS After ShortTerm Incubation on Solid Medium

This is a pre print version of the following article:

Original Citation:

Availability:

This version is available http://hdl.handle.net/2318/1679774 since 2018-10-31T09:12:23Z

Published version:

DOI:10.1007/s00284-016-1161-2

Terms of use:

Open Access

Anyone can freely access the full text of works made available as "Open Access". Works made available under a Creative Commons license can be used according to the terms and conditions of said license. Use of all other works requires consent of the right holder (author or publisher) if not exempted from copyright protection by the applicable law. 


\section{Rapid Identification of Microorganisms from Positive Blood Culture by MALDI- TOF MS After Short-Term Incubation on Solid Medium}

Antonio Curtoni, 1,

Phone +390116335247

Email antonio.curtoni@gmail.com

Raffaella Cipriani, 1

Email raffaella.cipriani23@gmail.com

Elisa Simona Marra, ${ }^{2}$

Email elisa.marra@alice.it

Anna Maria Barbui, 1

Emailabarbui@cittadellasalute.to.it

Rossana Cavallo, 1

Email rossana.cavallo@unito.it

Cristina Costa, 1

Email cristina.costa@unito.it

1 Microbiology and Virology Unit, Azienda Ospedaliero Universitaria Città della Salute e della Scienza di Torino, Corso Bramante 88, 10126 Turin, Italy

2 Bacteriology and Mycology Laboratory, Department of Public Health and Pediatrics, University of Turin, Turin, Italy

\section{Abstract}

Matrix-assisted laser-desorption/ionization time-of-flight (MALDI-TOF) mass spectrometry (MS) is a useful tool for rapid identification of microorganisms. Unfortunately, its direct application to positive blood culture is still lacking standardized procedures. In this study, we evaluated an easy- and rapid-to- 
perform protocol for MALDI-TOF MS direct identification of microorganisms from positive blood culture after a short-term incubation on solid medium. This protocol was used to evaluate direct identification of microorganisms from 162 positive monomicrobial blood cultures; at different incubation times (3, 5, $24 \mathrm{~h})$, MALDI-TOF MS assay was performed from the growing microorganism patina. Overall, MALDI-TOF MS concordance with conventional methods at species level was $60.5,80.2$, and $93.8 \%$ at 3,5 , and $24 \mathrm{~h}$, respectively. Considering only bacteria, the identification performances at species level were $64.1,85.0$, and $94.1 \%$ at 3,5 , and $24 \mathrm{~h}$, respectively. This protocol applied to a commercially available MS typing system may represent, a fast and powerful diagnostic tool for pathogen direct identification and for a promptly and pathogen-driven antimicrobial therapy in selected cases.

Antonio Curtoni and Raffaella Cipriani equally contributed to this study and share first authorship.

\section{Introduction}

An early and targeted antimicrobial treatment is relevant in order to decrease morbidity and mortality related to bloodstream infections [5, 14 14]. Reducing time for positive blood culture pathogen identification results in an appropriate antimicrobial therapy and improves patient management and outcome [5, 11 14]. Conventional methods for identifying microorganisms in clinical microbiology rely on microscopy, macroscopic features, and biochemical reactions. The majority of automated biochemical testing instruments has decreased labor and incubation times, but are still required up to $18-24 \mathrm{~h}$ to achieve a complete microbiological report $[6,13]$. In addition, not all microorganisms are easy to identify by biochemical methods. Several molecular techniques have been developed to detect pathogens, but due to their disadvantages, especially in blood stream infection application, they are still only recommended in addition to conventional phenotypic techniques $[1,3,6,13]$. Matrix-assisted laser-desorption/ionization time-of-flight (MALDITOF) mass spectrometry (MS) is a useful and robust tool that can rapidly and accurately identify microorganisms with a high degree of specificity and sensitivity $[3,15]$. Despite its undeniable potential in improving a timely diagnosis, the use of MALDI-TOF MS in bloodstream infection is limited by the fact that positive blood culture broths are not readily available for testing due to the interference of host proteins and resins or charcoal in blood culture specimens. Therefore, about $18-24 \mathrm{~h}$ should be required to obtain isolated colonies from solid subcultures to analyze. Different in-house methods and some commercial kits for sample preparation have been suggested to solve this 
limitation but they are associated to additional manual processing time and costs $[2,8,9,10,11,12]$. In the present study, we suggest an alternative, easy-toperform, and rapid approach applied to a commercially available mass spectrometry typing system for the identification of microorganisms from positive blood culture and analyze the method performance at different incubation times on solid medium.

\section{Materials and Methods}

Over a period of 2 months (from the 1st of June to the 31 st of July 2015), positive blood culture bottles, detected by BacT/ALERT 3D (bioMérieux, Marcy l'Etoile, France) instrument, were prospectively collected at the Microbiology and Virology Unit of Azienda Ospedaliero Universitaria Città della Salute e della Scienza di Torino (Turin, Italy). Samples were collected from patients with suspected sepsis; only one sample per patient was included in the study. After Gram staining observation, 162 monomicrobial samples were selected and followed two different ways of processing. In the first case, the routine workflow in use in our laboratory was adopted: two drops of positive broth were subcultured on the appropriate solid medium on the basis of the Gram staining observation (BD Columbia Agar with 5\% Sheep Blood, BD MacConkey II Agar, BD Columbia CNA Agar with 5\% Sheep Blood, BD Chocolate Agar, BBL CHROMAgar Candida Medium; Becton-Dickinson, Franklin Lakes, New Jersey, USA). After overnight incubation, identification and antimicrobial susceptibility testing were set up both on Microscan Walkaway plus System (Beckman Coulter, Brea, California, USA) for bacteria and on VITEK MS (bioMérieux) and on Sensititre YeastOne (ThermoScientific, Waltham, Massachusetts, USA) for yeasts, respectively. In the second case, two drops of positive blood culture were plated on BD Columbia Agar with 5\% Sheep Blood (Becton-Dickinson) and spread over the plate surface with a $10 \mu \mathrm{L}$ inoculation loop. The plate was incubated at $36 \pm 1{ }^{\circ} \mathrm{C}$ in $5 \% \mathrm{CO}_{2}$ for 3,5 , and $24 \mathrm{~h}$. At the end of incubation time, a thin layer of growing colonies was scraped from the plate and double spotted on a steel target plate. In case of yeasts or Gram-positive bacteria, in order to accelerate and improve identification, $0.5 \mu \mathrm{L}$ of $100 \%$ formic acid was added [8]. Subsequently, $1 \mu \mathrm{L}$ of matrix (alfa-cyano-4-hydroxycinnamic acid solution) (supplied with MALDI-TOF reagents) was added and air dried. MALDI-TOF MS assay was performed by the VITEK MS at 3, $5 \mathrm{~h}$, and at $24 \mathrm{~h}$ for comparison. Criteria for successful identification were achieved according to producer's instruction. Misidentification result was given when VITEK MS identification had a confidence level of $\geq 99.9 \%$ but did not match MicroScan Walkaway Plus System results or, in case of yeasts, VITEK MS identification from the $24 \mathrm{~h}$ subcultures. No identification was assigned when confidence level was $<99.9 \%$ or no identification was given by VITEK MS. For inferential 
statistics, Chi-square test and Fisher's test were used as appropriate. A $P$ value $<0.5$ was considered as statistical significant.

\section{Results}

Overall, of the 162 positive monomicrobial blood culture selected, 121 (74.7\%) of the isolated microorganisms were Gram-positive bacteria, 32 (19.8\%) Gramnegative bacteria, and $9(5.6 \%)$ yeasts. In comparison to conventional methods, MALDI-TOF MS rapid identification correctly identified isolates both at genus and species level at $3 \mathrm{~h}$ in $>60 \%$ (64.2 and 60.5\%, respectively) and at $5 \mathrm{~h}$ in $>80 \%$ ( 84.6 and $80.2 \%$, respectively) of the cases. Multiple identifications or no identification occurred in $32.7 \%$ and in $10.5 \%$ of the isolates at 3 and $5 \mathrm{~h}$, respectively (Fig. 1). The misidentification rate was $<5 \%$; in particular, at $5 \mathrm{~h}$, the rate was $4.9 \%$ for all microorganisms (Fig. 1) and was 3.9\% excluding yeasts. Considering only bacteria, at genus and species level, the identification performances were, at $3 \mathrm{~h}, 68.6$ and $64.1 \%$, and at $5 \mathrm{~h}, 89.5$ and $85.0 \%$, respectively. Considering only Gram-positive cocci, a correct identification was obtained at genus level in 68.1 and $92.2 \%$ of the samples at 3 and $5 \mathrm{~h}$, respectively. Multiple identifications or no identification occurred in $30.2 \%$ and only in $5.2 \%$ of the isolates at 3 and $5 \mathrm{~h}$, respectively. Misidentification rate was 1.7 and $2.6 \%$ at 3 and $5 \mathrm{~h}$, respectively. MALDI-TOF MS correct identification data at 3 and $5 \mathrm{~h}$ are summarized in Table 1. In details, Staphylococcus aureuspositive blood culture achieved a rapid identification in 85.7 and $100 \%$ of the cases at 3 and $5 \mathrm{~h}$, respectively, and Coagulase-negative Staphylococci (CoNS) in 60 and $88.2 \%$. Enterococci had comparable good results at $5 \mathrm{~h}$, in particular due to Enterococcus faecalis rate. Only one blood culture was positive for Streptococcus pneumoniae: the identification of genus was possible at $3 \mathrm{~h}$ and of species at $5 \mathrm{~h}$ of incubation time. As regards the 32 Gram-negative bacteria isolates, a correct identification was achieved in $78.1 \%$ of the cases at genus level and in $75 \%$ at species level at $3 \mathrm{~h}$ and in $90.6 \%$ and in $87.5 \%$ at $5 \mathrm{~h}$. Multiple identifications or no identification occurred in $21.9 \%$ and only in $6.3 \%$ of the isolates at 3 and $5 \mathrm{~h}$, respectively. Misidentification rate was of $0.0 \%$ at $3 \mathrm{~h}$, and of $3.1 \%$ at $5 \mathrm{~h}$. Considering only Enterobacteriaceae, the results were even better with a concordance with biochemical methods of $93.1 \%$ at species level at $5 \mathrm{~h}$. Worse results were obtained for Gram-positive rods at $5 \mathrm{~h}$ with only a correct identification rate of $20 \%$ at genus level. No successful identification was achieved for yeasts both at genus and species level at 3 or $5 \mathrm{~h}$ of incubation. MALDI-TOF MS assay was performed for comparison at $24 \mathrm{~h}$ had 95.7 and $93.8 \%$ of concordance with conventional identification methods for each isolated microorganism at genus and species level, respectively. Even in this case, Grampositive rods had poor identification rate, $40.0 \%$ both at genus and species level. Dividing blood culture samples into two groups, with positivity time at $<24$ 
and $>24 \mathrm{~h}$, we found that the percentage of correct identification was higher at genus level in the first group both at $3(67.4$ vs. $45.8 \%)$ and at 5 (86.5 vs. $70.8 \%)$ incubation hours. This difference was observed considering all the isolated microorganisms, but not for Gram-negative bacteria (Table 2). However, according to our data, no statistically significant relationship was found between positivity time of blood culture and correct identification of pathogens at any incubation time.

\section{Fig. 1}

MALDI-TOF MS performances for all microorganisms MALDI-TOF MS species and genus levels identification, multiple or no identification, and misidentification results at 3 and 5 h-incubation time.(Id. identification)

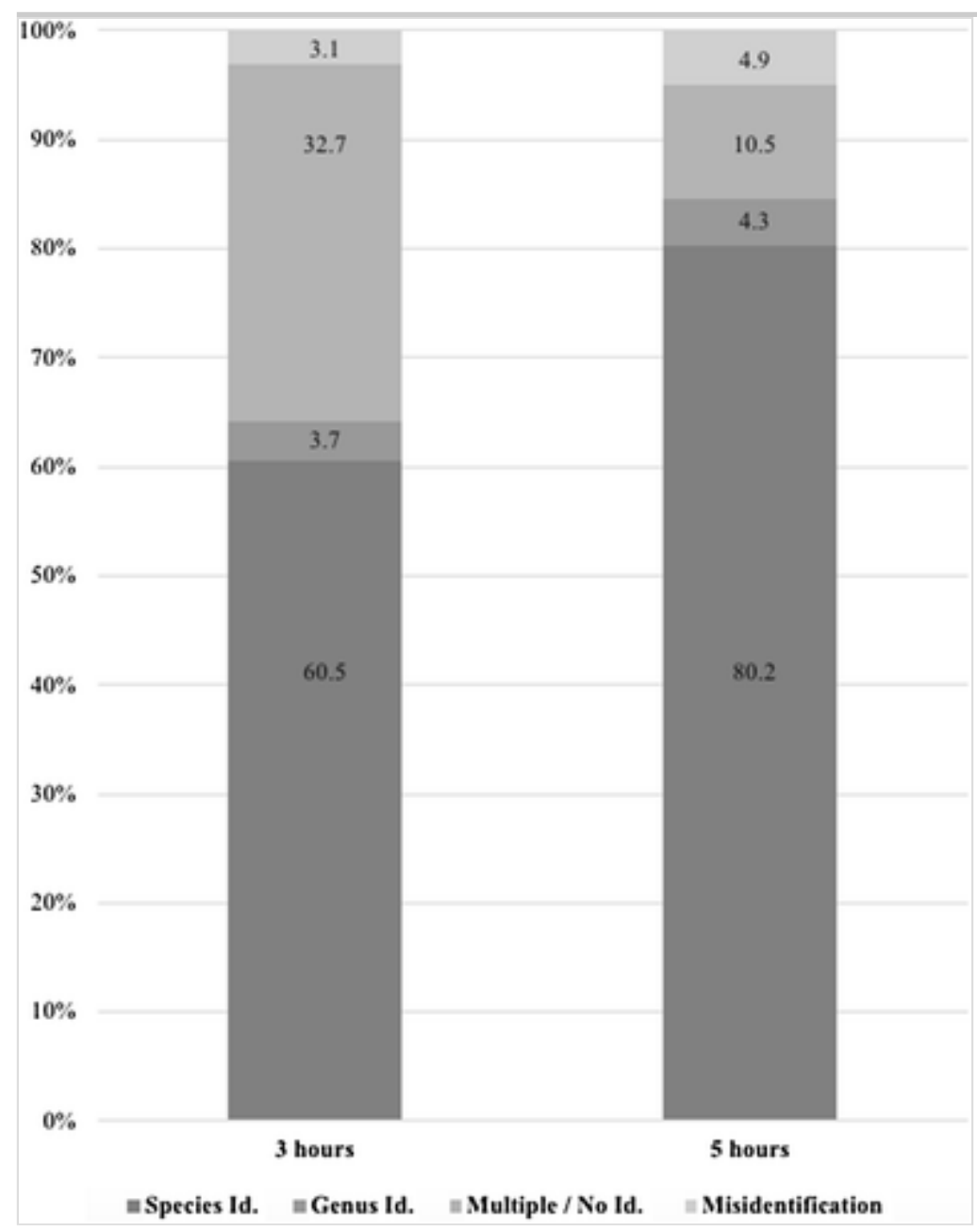

\section{Table 1}

MALDI-TOF MS identification results Concordance of MALDI-TOF MS identification $r$ 5 h-incubation time on solid medium with conventional phenotypic identification method species levels

MALDI-TOF MS identification results 


\begin{tabular}{|c|c|c|c|c|c|c|c|c|}
\hline & $\begin{array}{l}\text { Samples } \\
\text { n. }\end{array}$ & Genus & $\%$ & Species & $\%$ & Genus & $\%$ & $\mathbf{S p}$ \\
\hline $\begin{array}{l}\text { Gram-positive } \\
\text { bacteria }\end{array}$ & 121 & 79 & 65.3 & 74 & 61.2 & 108 & 89.3 & 10 \\
\hline \multirow{2}{*}{$\begin{array}{l}\text { Gram-positive } \\
\text { cocci }\end{array}$} & \multirow{2}{*}{116} & \multicolumn{5}{|c|}{ MALDI-TOF MS identification results } & \multirow{2}{*}{92.2} & \multirow[t]{2}{*}{10} \\
\hline & & $3 \mathrm{~h}$ & & & & $5 \mathrm{~h}$ & & \\
\hline Enterococci & 12 & 10 & 83.3 & 10 & 83.3 & 11 & 91.7 & 10 \\
\hline $\begin{array}{l}\text { Enterococcus } \\
\text { faecalis }\end{array}$ & $\begin{array}{l}\text { Samples } \\
\text { n. }\end{array}$ & $\stackrel{9}{\text { Genus }}$ & $\begin{array}{l}90.0 \\
\%\end{array}$ & $\stackrel{9}{\text { Species }}$ & $\begin{array}{l}90.0 \\
\%\end{array}$ & $\begin{array}{l}10 \\
\text { Genus }\end{array}$ & $\begin{array}{l}100.0 \\
\%\end{array}$ & $\begin{array}{l}10 \\
\mathbf{S p}\end{array}$ \\
\hline $\begin{array}{l}\text { Enterococcus } \\
\text { faecium }\end{array}$ & 1 & 0 & 0.0 & 0 & 0.0 & 1 & 100.0 & 0 \\
\hline $\begin{array}{l}\text { Enterococcus } \\
\text { gallinarum }\end{array}$ & 1 & 1 & 100.0 & 1 & 100.0 & 0 & 0.0 & 0 \\
\hline $\begin{array}{l}\text { Micrococcus } \\
\text { luteus }\end{array}$ & 1 & 1 & 100.0 & 1 & 100.0 & 1 & 100.0 & 1 \\
\hline Staphylococci & 99 & 66 & 66.7 & 63 & 63.6 & 92 & 92.9 & 89 \\
\hline $\begin{array}{l}\text { Staphylococcus } \\
\text { aureus }\end{array}$ & 14 & 12 & 85.7 & 12 & 85.7 & 14 & 100.0 & 14 \\
\hline $\begin{array}{l}\text { Coagulase- } \\
\text { Negative } \\
\text { Staphylococci }\end{array}$ & 85 & 54 & 63.5 & 51 & 60.0 & 78 & 91.8 & 75 \\
\hline $\begin{array}{l}\text { Staphylococcus } \\
\text { capitis }\end{array}$ & 3 & 2 & 66.7 & 2 & 66.7 & 3 & 100.0 & 3 \\
\hline $\begin{array}{l}\text { Staphylococcus } \\
\text { cohnii }\end{array}$ & 1 & 0 & 0.0 & 0 & 0.0 & 0 & 0.0 & 0 \\
\hline $\begin{array}{l}\text { Staphylococcus } \\
\text { epidermidis }\end{array}$ & 47 & 35 & 74.5 & 35 & 74.5 & 44 & 93.6 & 43 \\
\hline $\begin{array}{l}\text { Staphylococcus } \\
\text { haemolyticus }\end{array}$ & 11 & 5 & 45.5 & 4 & 36.4 & 10 & 90.9 & 9 \\
\hline $\begin{array}{l}\text { Staphylococcus } \\
\text { hominis }\end{array}$ & 20 & 11 & 55.0 & 10 & 50.0 & 19 & 95.0 & 19 \\
\hline $\begin{array}{l}\text { Staphylococcus } \\
\text { simulans }\end{array}$ & 1 & 1 & 100.0 & 0 & 0.0 & 1 & 100.0 & 0 \\
\hline $\begin{array}{l}\text { Staphylococcus } \\
\text { warneri }\end{array}$ & 2 & 0 & 0.0 & 0 & 0.0 & 1 & 50.0 & 1 \\
\hline Streptococci & 4 & 2 & 0.0 & 0 & 0.0 & 3 & 75.0 & 2 \\
\hline $\begin{array}{l}\text { Streptococcus } \\
\text { anginosus }\end{array}$ & 1 & 0 & 0.0 & 0 & 0.0 & 0 & 0.0 & 0 \\
\hline $\begin{array}{l}\text { Streptococcus } \\
\text { bovis }\end{array}$ & 1 & 0 & 0.0 & 0 & 0.0 & 1 & 100.0 & 1 \\
\hline
\end{tabular}




\begin{tabular}{|c|c|c|c|c|c|c|c|c|}
\hline \multirow[b]{3}{*}{$\begin{array}{l}\text { Streptococcus } \\
\text { dysagalactiae }\end{array}$} & \multirow[b]{3}{*}{1} & \multicolumn{7}{|c|}{ MALDI-TOF MS identification results } \\
\hline & & \multicolumn{4}{|l|}{$3 \mathrm{~h}$} & \multicolumn{3}{|l|}{$5 \mathrm{~h}$} \\
\hline & & 1 & 100.0 & 0 & 0.0 & 1 & 100.0 & 0 \\
\hline $\begin{array}{l}\text { Streptococcus } \\
\text { pneumoniae }\end{array}$ & $\begin{array}{l}\text { Samples } \\
\text { h. }\end{array}$ & Genus & $9 / 00.0$ & Species & 890 & Genus & 900.0 & $\mathrm{Sp}$ \\
\hline Gram-positive rods & 5 & 0 & 0.0 & 0 & 0.0 & 1 & 20.0 & 0 \\
\hline $\begin{array}{l}\text { Brevibacterium } \\
\text { casei }\end{array}$ & 2 & 0 & 0.0 & 0 & 0.0 & 0 & 0.0 & 0 \\
\hline $\begin{array}{l}\text { Corynebacterium } \\
\text { striatum }\end{array}$ & 2 & 0 & 0.0 & 0 & 0.0 & 1 & 50.0 & 0 \\
\hline $\begin{array}{l}\text { Propionibacterium } \\
\text { acnes }\end{array}$ & 1 & 0 & 0.0 & 0 & 0.0 & 0 & 0.0 & 0 \\
\hline $\begin{array}{l}\text { Gram-negative } \\
\text { bacteria }\end{array}$ & 32 & 25 & 78.1 & 24 & 75.0 & 29 & 90.6 & 28 \\
\hline Enterobacteriaceae & 29 & 23 & 79.3 & 23 & 79.3 & 27 & 93.1 & 27 \\
\hline $\begin{array}{l}\text { Enterobacter } \\
\text { cloacae/asburiae }\end{array}$ & 4 & 4 & 100.0 & 4 & 100.0 & 4 & 100.0 & 4 \\
\hline Escherichia coli & 10 & 8 & 80.0 & 8 & 80.0 & 10 & 100.0 & 10 \\
\hline Klebsiella oxytoca & 2 & 2 & 100.0 & 2 & 100.0 & 2 & 100.0 & 2 \\
\hline $\begin{array}{l}\text { Klebsiella } \\
\text { pneumoniae }\end{array}$ & 9 & 6 & 66.7 & 6 & 66.7 & 8 & 88.9 & 8 \\
\hline $\begin{array}{l}\text { Morganella } \\
\text { morganii }\end{array}$ & 1 & 1 & 100.0 & 1 & 100.0 & 1 & 100.0 & 1 \\
\hline Proteus mirabilis & 3 & 2 & 66.7 & 2 & 66.7 & 2 & 66.7 & 2 \\
\hline $\begin{array}{l}\text { Non-fermenting } \\
\text { Gram-negative } \\
\text { bacteria }\end{array}$ & 3 & 2 & 66.7 & 1 & 33.3 & 2 & 66.7 & 1 \\
\hline $\begin{array}{l}\text { Acinetobacter } \\
\text { lwoffi }\end{array}$ & 1 & 0 & 0.0 & 0 & 0.0 & 0 & 0.0 & 0 \\
\hline $\begin{array}{l}\text { Aeromonas } \\
\text { hydrophila }\end{array}$ & 1 & 1 & 100.0 & 0 & 0.0 & 1 & 100.0 & 0 \\
\hline $\begin{array}{l}\text { Stenotrophomonas } \\
\text { maltophilia }\end{array}$ & 1 & 1 & 100.0 & 1 & 100.0 & 1 & 100.0 & 1 \\
\hline Yeasts & 9 & 0 & 0.0 & 0 & 0.0 & 0 & 0.0 & 0 \\
\hline
\end{tabular}




\begin{tabular}{|c|c|c|c|c|c|c|c|c|}
\hline \multirow[b]{3}{*}{ Candida albicans } & \multirow[b]{3}{*}{4} & \multicolumn{7}{|c|}{ MALDI-TOF MS identification results } \\
\hline & & \multicolumn{4}{|l|}{$3 \mathrm{~h}$} & \multicolumn{3}{|l|}{$5 \mathrm{~h}$} \\
\hline & & 0 & 0.0 & 0 & 0.0 & 0 & 0.0 & 0 \\
\hline $\begin{array}{l}\text { Candida } \\
\text { parapsilosis }\end{array}$ & $\begin{array}{l}\text { Samples } \\
\text { n. }\end{array}$ & $\stackrel{0}{\text { Genus }}$ & $\begin{array}{l}0.0 \\
\%\end{array}$ & $\stackrel{0}{\text { Species }}$ & $\begin{array}{l}0.0 \\
\%\end{array}$ & $\stackrel{0}{\text { Genus }}$ & $\begin{array}{l}0.0 \\
\%\end{array}$ & $\begin{array}{l}0 \\
\text { Sp }\end{array}$ \\
\hline $\begin{array}{l}\text { Torulopsis } \\
\text { glabrata }\end{array}$ & 3 & 0 & 0.0 & 0 & 0.0 & 0 & 0.0 & 0 \\
\hline Total & 162 & 104 & 64.2 & 98 & 60.5 & 137 & 84.6 & 13 \\
\hline
\end{tabular}

Table 2

Positivity time of blood culture and MALDI-TOF MS correct identification

\begin{tabular}{|c|c|c|c|c|}
\hline \multirow{3}{*}{$\begin{array}{l}\text { Incubation time } \\
\text { Blood culture positivity } \\
\text { time }\end{array}$} & \multicolumn{4}{|c|}{$\begin{array}{l}\text { MALDI-TOF MS correct identification at genus level } \\
(\%)\end{array}$} \\
\hline & \multicolumn{2}{|l|}{$3 \mathbf{h}$} & \multicolumn{2}{|l|}{$5 \mathrm{~h}$} \\
\hline & $<24 \mathrm{~h}$ & $>24 \mathrm{~h}$ & $<24 \mathrm{~h}$ & $>24 \mathrm{~h}$ \\
\hline Microorganisms & 67.4 & 45.8 & 86.5 & 70.8 \\
\hline Bacteria & 69.0 & 55.0 & 88.5 & 85.0 \\
\hline Gram-positive cocci & 64.6 & 56.3 & 89.2 & 87.5 \\
\hline Gram-negative bacteria & 81.8 & 100.0 & 86.4 & 100.0 \\
\hline
\end{tabular}

\section{Discussion}

In this study we evaluated the performance of MALDI-TOF MS for direct identification of microorganisms from positive blood cultures. MALDI-TOF MS direct identification for Gram-positive cocci and Gram-negative bacteria achieved good results with concordance with conventional methods near to $90 \%$ at genus and $>85 \%$ at species level in $5 \mathrm{~h}$-incubation time. Considering only Gram-positive cocci, as already described in previous studies, Staphylococcus aureus had the best identification results, whereas the less good results were 
obtained with Streptococci's group, although the isolates number was low. In addition, we observed good results for CoNS after only $5 \mathrm{~h}$ of incubation with no misidentification as Staphylococcus aureus and an identification rate at $5 \mathrm{~h}$ of $88.2 \%$ at species level. This could be a critical point in the interpretation of bloodstream infection etiology, as it could allow for a rapid discrimination between true pathogens and possible contaminants. As reported in literature and showed by our results, the use of formic acid significantly improves identification performance for Gram-positive bacteria and has to be considered mandatory [4, 8]. Considering Gram-negative bacteria, Enterobacteriaceae had the highest identification rate, whereas unsatisfactory results were obtained for non-fermenting Gram-negative bacteria as well as for Gram-positive rods and yeast with no identification at species level even at $5 \mathrm{~h}$-incubation time. However, as regards the Gram-positive rods, this should be considered in terms of clinical relevance, as Gram-positive rods are often considered contaminants. These unsatisfactory findings are probably due to microorganism intrinsic low growth rate. For this reason, it could be hypothesized that low blood culture positivity time (i.e., $<24 \mathrm{~h}$ ) could correlate with better results in identification due to a higher microorganism load and/or an intrinsic microorganism shorter time of growing. However, even if in terms of percentage, this hypothesis seems to be correct, with the exception of Gram-negative Bacteria, the correlation resulted not statistically significant.

At moment, for direct identification of microorganisms from positive blood culture bottles, several in-house protocols and some commercial kits have shown good results, however many of them are laborious, time consuming, or expensive. On the basis of literature data and considering our laboratory workflow, we have chosen and evaluated the most suitable, rapid, and costsaving method for direct MALDI-TOF MS pathogen identification from positive blood culture samples. In particular, we tested the identification performance of VITEK MS platform combined with rapid subculture method on solid medium. Few studies have focused on this combination as most of them are based on another commercial platform, Bruker MALDI Biotyper System or protocols such as serum-separator, lysis-filtration, spin-lysis, and others. [2, 8, 9, 10, 11, 12]. Comparison of ours with those obtained from other studies could be difficult due to different instrumentation in use, several samples processing, various number of testing replicates and assorted MALDI-TOF MS results analysis, or interpretation rules. According to Martinez et al., data obtained with the commercial Bruker Sepsityper kit (Bruker Daltonics), on Bruker MALDI Biotyper System, performances of our protocol at $5 \mathrm{~h}$ were encouraging and even higher considering Staphylococci, Streptococci, and Enterobacteriaceae (89.9 vs. $87.9 \%$; 50.0 vs. $42.9 \%$; 93.1 vs. $91.4 \%$ ) with low processing time (few seconds vs. $\geq 5 \mathrm{~min})$, labor, and costs [10]. Monteiro et al., in their proposed 
protocol, used the same identification platform VITEK MS, but a centrifugationbased method for fast and direct bacteria identification. Their results were better for Gram-negative bacteria ( 99.0 vs. $87.5 \%$ at $5 \mathrm{~h}$ ) but not for Gram-positive bacteria ( 82.3 vs. $84.3 \%$ at $5 \mathrm{~h}$; CoNS 77.3 vs. $88.2 \%$ at $5 \mathrm{~h}$ ); moreover, $>42 \mathrm{~min}$ with several processing steps were required [12]. In comparison to the study by Vereroken et al. applying the same rapid protocol based on $5 \mathrm{~h}$ subculture on solid media used in the present study, but different identification platform (VITEK MS vs. Bruker MALDI Biotyper System), we achieved for monomicrobial culture better results on Gram-positive bacteria in general ( 84.3 vs. $82.2 \%$ ) and, in particular, for Staphylococci and Staphylococcus aureus (89.9 vs. $85.6 \% ; 100.0$ vs. $95.5 \%$ ) [15]. In a similar study, using a short 4 hincubation method on solid medium combined with Bruker MALDI Biotyper System, Kohlmann et al. applied some variations: single replicate testing, chocolate agar as solid medium, and two ways of interpretation of results, with manufacturer and modified cut-off values. In comparison to Kohlmann et al. findings, adopting manufacturer recommended cut-off values, our method was superior, or at least equal, even at 3 h-incubation time (61.2 vs. $33.3 \%$ Grampositive bacteria; 63.8 vs. $37.3 \%$ Gram-positive cocci; 0.0 vs. $0.0 \%$ Grampositive rods; 0.0 vs. $0.0 \%$ yeasts) with the exception of Gram-negative bacteria (75.0 vs. $96.4 \%$; 79.3 vs. $97.3 \%$ Enterobacteriaceae) [7]. The correct identification gap between the study by Kohlmann et al. with modified cut-off values and our results at $5 \mathrm{~h}$-incubation time was reduced, although our performances were still competitive ( 84.3 vs. $60.8 \%$ Gram-positive bacteria; 87.9 vs. $67.5 \%$ Gram-positive cocci; 89.9 vs. $66.5 \%$ Staphylococci; 0.0 vs. $0.0 \%$ yeasts) with same exceptions, as for examples, Enterococci, Streptococci, Grampositive rods, and Gram-negative bacteria in general [7]. This comparison suggests that even with $1 \mathrm{~h}$ less of incubation time and a single replicate testing, a modification on manufacturer's criteria for successful identification, could improve results and a similar adjustment could improve also our performances. Nevertheless, our protocol is especially designed for routine clinical microbiology laboratory. Even if an evaluation of patients' outcome has to be performed, as supported by Idelevich et al. results, we suggest its application after $5 \mathrm{~h}$ of incubation time in particular for Gram-positive cocci and Gramnegative bacteria as a good compromise between identification rapidity and accuracy [4]. In our experience, this method is not applicable for rapid identification of yeasts. For these reasons, we suggest the application of this protocol only on the bases of Gram staining observation in order to limit possible diagnostics errors, time wasting, or useless labor.

Some factors could have limited the relevance of our results, in particular the small specimen number, the limited variety of species, and the exclusion of polymicrobial samples. Further studies should include more isolates and protocol 
evaluation in the presence of polymicrobial infections. Moreover, in the future, in order to improve our protocol's performances for fastidious bacteria and Haemophilus spp., it should be recommendable to incubate samples on chocolate agar as suggested by Kohlmann et al. [7].

Conventional methods for microorganism identification and susceptibility testing in bloodstream infections provide a complete microbiological report useful for the therapeutic management of the patient after about 24-48 h [6, 13]. Even if conventional methods are considered the gold standard, several microbiology laboratories have incorporated in their routine workflow MALDI-TOF MS rapid protocols in order to accelerate microorganism identification and timely shift from empirical to targeted antimicrobial therapy [12]. The proposed method is easy to integrate in the clinical laboratory routine, not requiring additional timeor labor-consuming sample preparation steps, and leads to adequate identification results available to the clinician within the same day of blood culture positivity. The commercial platform VITEK MS combined with a rapid solid subculture method directly from positive blood culture samples after Gram staining observation could represent a relevant implementation in the diagnostic workflow of blood stream infections. In fact, Gram staining remains a key information even in the presence of a powerful instrument such as MALDI-TOF MS. Although a larger number of samples and species needs to be analyzed, these preliminary results could be considered for a timely therapeutic choice based on the epidemiological data about antimicrobial susceptibility in the hospital and in each ward. Thus, MALDI-TOF MS rapid identification represents a very powerful diagnostic tool for promptly and pathogen-driven antimicrobial therapy. Further studies, beside considering higher number of specimen, should also evaluate MALDI-TOF MS-based approach in relationship to patient's outcome.

$\mathrm{AQ} 2$

Funding This research did not receive any specific grant from funding agencies in the public, commercial, or not-for-profit sectors.

Compliance with Ethical Standards

Conflict of interest The authors declare that they have no conflict of interest.

Ethical Approval "All procedures performed in studies involving human participants where in accordance with the ethical standards of the institutional and/or national research committee and with the 1964 Helsinki declaration and its later amendments or comparable ethical standards." 


\section{References}

1. Chang SS, Hsieh WH, Liu TS, Lee SH, Wang CH, Chou HC, Yeo YH, Tseng CP, Lee CC (2013) Multiplex PCR system for rapid detection of pathogens in patients with presumed sepsis - a systemic review and metaanalysis. PLoS ONE 8(5):e62323. doi:10.1371/journal.pone.0062323

\section{Gray TJ, Thomas L, Olma T, Iredell JR, Chen SC (2013) Rapid} identification of Gram-negative organisms from blood culture bottles using a modified extraction method and MALDI-TOF mass spectrometry. Diagn Microbiol Infect Dis 77(2):110-112. doi:10.1016/j.diagmicrobio.2013.06.016

3. Idelevich EA, Becker K (2016) Identification and susceptibility testing from shortly incubated cultures accelerate blood culture diagnostics at no cost. Clin Infect Dis 62(2):268-269. doi:10.1093/cid/civ824

4. Idelevich EA, Schüle I, Grünastel B, Wüllenweber J, Peters G, Becker K (2014) Rapid identification of microorganisms from positive blood cultures by MALDI-TOF mass spectrometry subsequent to very short-term incubation on solid medium. Clin Microbiol Infect 20(10):1001-1006. doi:10.1111/14690691.12640

5. Kerremans JJ, Verboom P, Stijnen T, Hakkaart-van Roijen L, Goessens W, Verbrugh HA, Vos MC (2008) Rapid identification and antimicrobial susceptibility testing reduce antibiotic use and accelerate pathogen-directed antibiotic use. J Antimicrob Chemother 61(2):428-435 Epub 2007 Dec 21

6. Klouche M, Schröder U (2008) Rapid methods for diagnosis of bloodstream infections. Clin Chem Lab Med 46(7):888-908. doi:10.1515/CCLM.2008.157

7. Kohlmann R, Hoffmann A, Geis G, Gatermann S (2015) MALDI-TOF mass spectrometry following short incubation on a solid medium is a valuable tool for rapid pathogen identification from positive blood cultures. Int J Med Microbiol 305(4-5):469-479. doi:10.1016/j.ijmm.2015.04.004

8. La Scola B, Raoult D (2009) Direct identification of bacteria in positive blood culture bottles by matrix-assisted laser desorption ionisation time-offlight mass spectrometry. PLoS ONE 4(11):e8041.

doi:10.1371/journal.pone.0008041 
9. Machen A, Drake T, Wang YF (2014) Same day identification and full panel antimicrobial susceptibility testing of bacteria from positive blood culture bottles made possible by a combined lysis-filtration method with MALDI-TOF VITEK mass spectrometry and the VITEK2 system. PLoS ONE 9(2):e87870. doi:10.1371/journal.pone.0087870

10. Martinez RM, Bauerle ER, Fang FC, Butler-Wu SM (2014) Evaluation of three rapid diagnostic methods for direct identification of microorganisms in positive blood cultures. J Clin Microbiol 52(7):2521-2529.

doi:10.1128/JCM.00529-14

11. Mestas J, Felsenstein S, Bard JD (2014) Direct identification of bacteria from positive BacT/ALERT blood culture bottles using matrix-assisted laser desorption ionization-time-of-flight mass spectrometry. Diagn Microbiol Infect Dis 80(3):193-196. doi:10.1016/j.diagmicrobio.2014.07.008

12. Monteiro J, Inoue FM, Lobo AP, Sugawara EK, Boaretti FM, Tufik S (2015) Fast and reliable bacterial identification direct from positive blood culture using a new TFA sample preparation protocol and the VITEK ${ }^{\circledR}$ MS system. J Microbiol Methods 109:157-159. doi:10.1016/j.mimet.2014.12.009

13. Paolucci M, Landini MP, Sambri V (2010) Conventional and molecular techniques for the early diagnosis of bacteraemia. Int J Antimicrob Agents 36(Suppl 2):S6-16. doi:10.1016/j.ijantimicag.2010.11.010

14. Paul M, Shani V, Muchtar E, Kariv G, Robenshtok E, Leibovici L (2010) Systematic review and meta-analysis of the efficacy of appropriate empiric antibiotic therapy for sepsis. Antimicrob Agents Chemother 54(11):48514863. doi:10.1128/AAC.00627-10

15. Verroken A, Defourny L, Lechgar L, Magnette A, Delmée M, Glupczynski Y (2015) Reducing time to identification of positive blood cultures with MALDI-TOF MS analysis after a 5-h subculture. Eur J Clin Microbiol Infect Dis 34(2):405-413. doi:10.1007/s10096-014-2242-4 